\title{
A STUDY OF QUALITY OF WORK LIFE AMONG OFFICE STAFF IN AN AUTOMOBILE INDUSTRY
}

\author{
Muhammed Irfad P', H Ramakrishna ${ }^{2}$ \\ ${ }^{\text {I}}$ Student M.Tech-MEM, DSCE, Department of Industrial Engineering \&Management, DSCE Bangalore, Karnataka, \\ India \\ ${ }^{2}$ HOD, Department of Industrial Engineering \&Management, DSCE Bangalore, Karnataka, India
}

\begin{abstract}
Quality of work life refers to the level of happiness and dissatisfaction with one's career. There is an attempt to look the quality of work life among workers with special reference to Automobile industry in Bangalore. The research design chosen is descriptive in nature. The sample size taken to conduct the research is 1 workers. Questionnaire method was used for primary data collection. Secondary data was collected from earlier research work, journals, websites and online articles. Simple percentage analysis and chi- square test are the tools used for the data analysis. The investigation remarkably pointed out the major factors that influence and decide the Quality of work life are attitude, nature of jobs, stress level, career, growth and development and rewards. This study helps for HR practices to design programs for improving $Q W L$.
\end{abstract}

Keywords - Quality of work life, Job satisfaction, Motivation, Employee satisfaction. $* * *$

\section{INTRODUCTION}

Nature of work life means all the progressive wellsprings of information which go for the specialist's satisfaction and updating definitive suitability. The key aim is to make occupations and working conditions that are astounding for agents and furthermore money related quality of affiliation. It insinuates the level of satisfaction, motivation, obligation and incorporation an individual association with respect to their line at the work. The Quality of work life is the level off lawlessness acknowledged work and working conditions that add to the general satisfaction \& execution essentially at individual level in conclusion at affiliation level. Nature of Work Life has ended up being a champion among the most basic issues these days in every affiliation. Laborers are the oblige that is behind each successful affiliation. No affiliation can twist up discernibly viable with development essentially in light of the fact that for the usage of advancement moreover, affiliations require strong work propel. Nature of Work Life was the term truly exhibited in the late 1960's. From that period till now the term is expanding progressively criticalness all over, at each work put. At first Quality of work life was focusing on the effects of work on the general thriving and the prosperity of the authorities. However, now its focus has been changed. Every affiliation need to give incredible condition to their authorities including all cash related and non budgetary inspirations with the objective that they can hold their agents for the more amplified period and for the achievement of the affiliation destinations.. At the end we can express that a chipper and strong agent will give better turnover, utilize sound judgment and firmly add to the affiliation objective. The Quality of work life is a strategy by which an affiliation responds to agent necessities for making framework that empowers them to share totally in settling on decision that layouts by which an their by which an life by which an at by which an work. Along these lines QWL infers having awesome supervisi $\mathrm{n}$, incredible $\mathrm{w}$ rking $\mathrm{c}$ nditi $\mathrm{ns}$, and intriguing, testing and compensating work.

\section{FACTORS AFFECTING QUALITY OF WORK} LIFE

Job satisfaction:- Work fulfillment is the colossal or unpropitious with which delegates see their work. Correspondingly as with motivation, it is impacted by nature. Work fulfillment is influenced by occupation arrange. Occupations that are rich in positive behavioral parts, for instance, self-run, arrangement, undertaking character, errand importance and feedback add pleasant to delegate. Thus, presentation is basic in light of the fact that the specialist's affirmation by the work amass adds to fulfillment.

Pay:- Nature of work life is fundamentally worked around the idea of impartial pay. Presently a daysahead, laborers might need to take part in the benefit of the association.

People: - Nearly everyone necessities to oversee 3 game plan of people in the $\mathrm{w}$ rk put. Those are to be particular supervisor, relates in a comparable level and subordinates. Beside this, a couple of reasons for living require relationship with people like patients, media individuals, open, customers, gangsters, cheats, physically disabled people, stupid, adolescents, outside delegates, crooks, legislators, open figures and huge names. These conditions ask for unusual condition of reasonability, cool temper, class, amusingness, liberality, technique and affectability.

Health condition:- Organization ought to comprehend that their actual riches lies in their specialists thus giving healthyenvironment to workers ought to be their essential target. 
Participative administration style and acknowledgment:Level affiliation structure enables relationship to support delegate intrigue.

Inspiration:- Inspiration is a psyche boggling subject. 1t incorporates the surprising feelings, thoughts and past experiences of each of us as we offer an arrangement of associations inside and outside affiliations. To expect a singular motivational approach work in every condition is in all likelihood unrealistic. Without a doubt, even researchers and investigates take changed points of view about motivation. Coincidentally, motivation can be described as a man's drive to make a move since that individual needs to do accordingly. People act since they feel that they have to. Regardless, if they are moved they settle on the positive choice to speak to a reason in light of the fact that, for example, it may fulfill some of their needs.

Work life balance:- Association should give the loosening up time to specialists and offer tips to modify their own particular and master lives. They should not strain delegates individual and social life by convincing on them by asking for working hours, additional minutes work, business travel, un timing trades. By the globalization the present day delegates are experiencing inconvenience. To address the troubles acted by present rules, legitimate must fixation their thought in bringing a congruity between work life and individual life. The basic doubt is that work life alter will finally ensure Quality of work life.

\section{NEED OF THE STUDY}

In the current circumstance every affiliation envisions that their specialists will perform at their zenith potential. In spite of the way that monetary points of view expect a basic part in influencing laborers, relationship around the world have come to fathom that there are various diverse edges that contributes better illustrative execution. It is these perspectives that casing the explanation behind this survey. Particularly this survey arrangements to recognize the distinctive unmistakable and vague points of view that add to the way of the workplace. It is basic for a relationship to make an astoundingly supportive work environment for delegates. This survey is relied upon to ensure that all specialists are performing at their apex potential, free from tension, and to ensure each one of their needs are totally satisfied. This survey will be used as feedback from agents to know their present point of view of work environment and furthermore to identify the ranges of change for the association.

\section{SCOPE OF THE STUDY}

The term Quality of work life in its more broad sense covers diverse parts of business and non-work conditions of work. This audit covers the general way of work life of agents, i.e. their occupation satisfaction, work environment, working hours, work extend, their association with their partners, work assignments, establishment gave et cetera.The present audit goes for measuring the level of satisfaction of agents $\&$ to consider the distinctive welfare activities and favorable circumstances obliged the delegates. The survey is liable to the appraisal imparted by each one of the delegates of the extensive number of divisions. Nature of work life is a multi dimensional point. Some of these edges are Compensation and the reward for the work.

\section{SIGNIFICANCE OF THE STUDY}

QWL covers the distinctive perspectives under the general umbrella of enduring affiliation direct. In this way the nature of work life should be broad in its augmentation. Survey the demeanor of specialists towards workforce approaches. The exploration will be useful in under standing the present position of the association. What's more, give a few techniques to broaden the worker fulfillment with little adjustment which depends on the inside offices of the association. The exploration can be additionally used to assess the offices given by the administration towards the representative. This review likewise controls the desires of the representatives.

\section{ABOUT THE COMPANY}

The Volvo Group is a Swedish multinational delivering organization headquartered in Gothenburg. While its insideactivity-is-the-era, -scattering-and-offer-of-trucks,transports- and-improvement-equipment. Volvo also supplies marine and current drive structures and cash related organizations. The Volv Group has first experience with the world in 1927, when the essential Volvo auto gotten off the creati $\mathrm{n}$ line at the firm in Gothenburg. Only 28 cars were conveyed that year. The primary truck, the "Game plan 1", released in January 1928, as an incite accomplishment and pulled in thought in the around the world. In 193 , Volvo sold 639 automobiles, and the charge of trucks to Europe started quick after; the cars did not twist up obviously standard outside Sweden until after World War II.

Pentaverken, who had created engines for Volvo, was picked up in 1935, dealing with a secured supply of engines and access into the marine engine advertise. The AB Volvo Group is one of the world's optimal and driving makers of trucks, transports, advancement apparatus and marine and present day engines. The Volvo Group furthermore introduced the workplace financing and organization. The Volvo Group, with its focal station in Gothenburg, uses around 1 , number of people, has era workplaces in 18 countries and trade its things more than 19 markets wherever all through the world.

\section{GAPS IN LITERATURE}

I understood that problems in QWL can be reduced by many methods. The authors in the above paper have explained about the workdone to improve the Nature of work life and satisfaction. To finish that they utilized apparatuses, for example, basic rate examination, chi-square test, ANOVA, and survey strategy. It is obvious that from the above papers that survey strategy is the strong apparatus for lessen the issues. This approach spurs individuals by fulfilling their financial needs as well as their social and mental ones. 


\section{RESEARCH METHEDOLOGY}

An examination is watchful inquiry; especially through scan for new actuality in any branch of learning. It is a systemized push to acquire knowledge.Research methodology is the way to systematically solve the investigate issue It might be comprehended as a study of examining how research is done deductively. It is important for their searcher to know the examination strategies or strategy as well as the procedure. Scientist dependably needs to comprehend the supposition underline different system and they have to know the criteria by which they can choose that specific strategy and methods will be material to certain issue and other won't.

\section{RESULT}

\subsection{Reliability Test}

Reliability test was conducted using Microsoft Excel. The entire data was fed into the software it was ensured that the data was fed properly without any flaws and any errors. Following to the same the Chronbach's Alpha was to be found. The entire data was selected and the function was applied. The Chronbach's Alpha coefficient was found to be .87 which was well above the threshold value of .7. Thus, the instrument i.e. the questionnaire form was found to be reliable

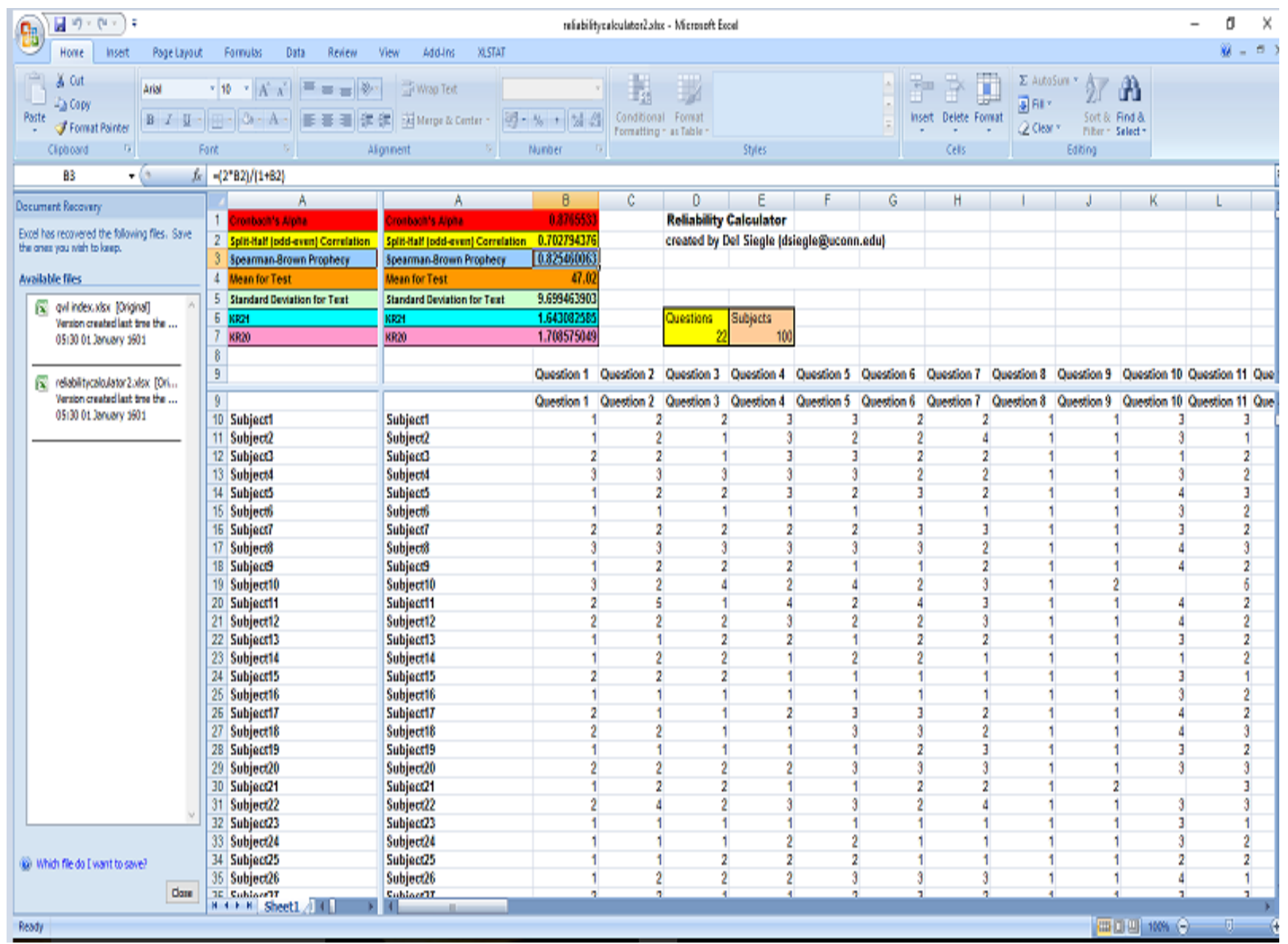

Figure representing Screen shot of Reliability calculator

\subsection{Data Analysis}

The survey conducted in a autobile company the rspondents $84 \%$ are from male and $16 \%$ are from female.

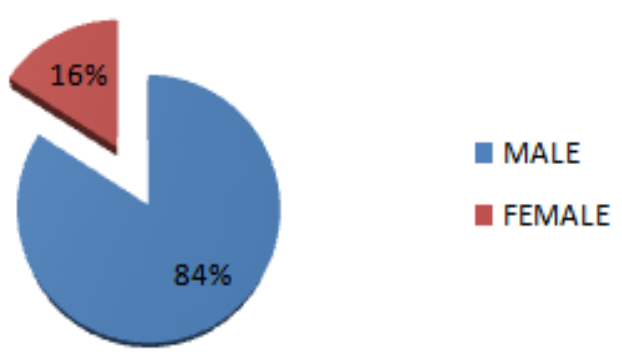

Figure representing the no. of gender respondents 
In this survey identified that $22 \%$ are age group of $2-3$ years, $65 \%$ and $15 \%$ are collected from age group of $31-45$ years and above 45 years respectively

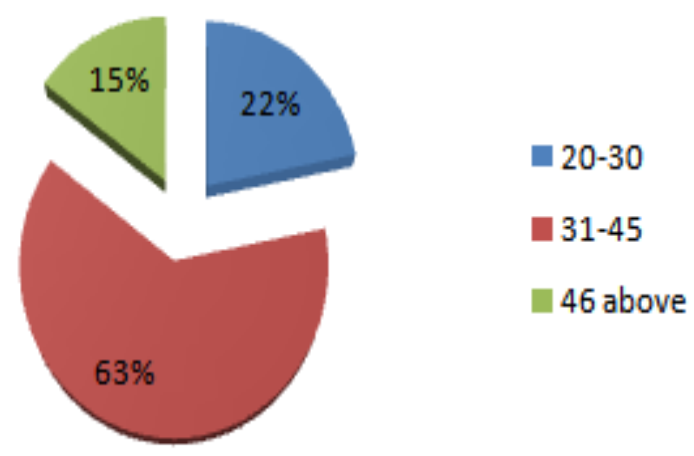

Figure representing the age group of respondents

Also undergo with the experience analysis in that $13 \%$ are from $<1$ year experience $21 \%$ are from $1-5$ years experience $36 \%$ of respondents are from $6-1$ years and $3 \%$ are from $>1$ years of experience. Also survey taken from qualification basis $42 \%$ of the respondents are Diploma candidates $41 \%$ of respondents are Graduate in various degree and $17 \%$ of the respondents are Post Graduates.

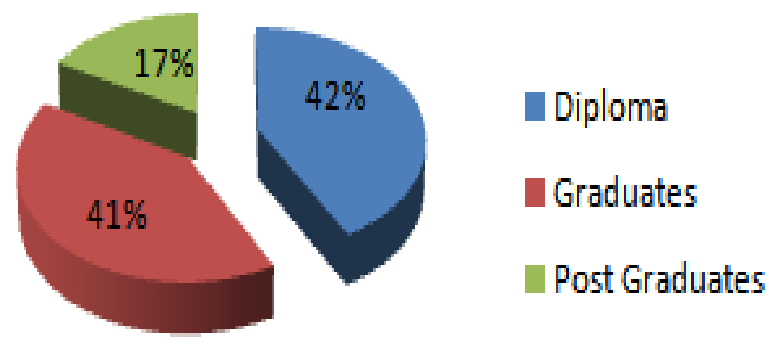

Figure representing Education qualification of respondents

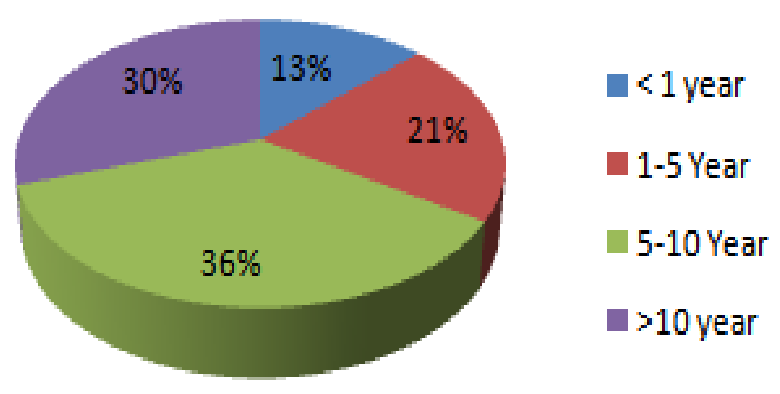

Figure representing Experience of Respondents

The survey conducted in industry by using questionnaire method. Questions are related to quality of work life and employee satisfaction. Most of the workers are happy with their organization but also some workers are dissatisfied with many things like promotions, salary, stress level, career development team etc.

\section{DISCUSSION AND CONCLUSION}

This study examines the level of QWL in automobile industry. Overall the findings of the present study have provided answer to the research questions. This study revealed that majority of workers has considered all dimensions of QWL investigated in this study as favorable. It was evident that value growth and development, physical environment, work place integration, supervision, participation and pay and benefits. After discussion and take out from the survey find out some general observations.

$\checkmark \quad$ Majority ofthe employees are satisfied withsalary

$\checkmark \quad$ Majorityof the employees are satisfied with benefits.

$\checkmark \quad$ Majorityof the employees are satisfied with their work space and work assignment.

$\checkmark \quad$ Majority of the employees are satisfied with transfer policies but some of the employees are dissatisfied with their transfer policies.

$\checkmark \quad$ Majority of the employees are satisfied with the quality, quantity and rate of food in the canteen.

$\checkmark \quad$ The superiors are cooperative.

$\checkmark \quad$ Interaction between superiors and employees are good.

$\checkmark$ Maintenance and service of electrical and computer appliances are good.

$\checkmark$ Rectification/repair is done instantly.

$\checkmark$ Majority of the employees feel that the ventilation is good.

$\checkmark \quad$ Majority of the employees feel that the infrastructure facilities are good.

$\checkmark \quad$ Many of the employees have positive opinion towards the quality of work life in the organization.

$\checkmark \quad$ Majority of the employees arehaving job security.

$\checkmark$ Some of the employees are partially satisfied with the pay structure in the rganization.

This study highlighted that some positive aspects of the QWL among workers. This study provides valuable information about the how employees in the organization. After discussion find out with some suggestions.

$\checkmark$ The organization can review the promotion policies.

$\checkmark$ The organization can review the pay scale of the workers.

$\checkmark$ The organization can provide effective training for workers.

$\checkmark \quad$ The organization can concentrate on transfer policies.

$\checkmark$ The organization can review the fringe benefits.

$\checkmark$ The organization can improve the bus/cab facilities from and to the office.

$\checkmark \quad$ The organization improves the job security.

$\checkmark$ The organization can improve the career development programme.

$\checkmark \quad$ Majority of the workers are stressful during the work time. Organization should take care of some stress release programme to improve efficient result of the product.

All these suggestions prove effective and useful if awareness among the workers to different aspects of QWL is improved. Management have to strive hard to enlighten its employees on the advantages of different aspects of QWL such as education, health and other facilities. Every 
company has to satisfy some of the basic needs and demands of the workers because the satisfied and motivated workers are the source of achieving the organizational goals and obje-ctives. From the study it's clear that the overall quality of work life of the employees is good in the automobile industry, Bangalore.T his research highlights some of the gaps in employee's satisfaction tow-ards the quality of work life.

\section{REFERENCES}

[1]. ZHU Su-li "The Treadmill Effect on the Utility of Quality of Working Life" School of Management,Huazhong University of Science and Technology, P.R.China.- 1-4244-2388- / 8/\$2 . C2 8 IEEE

[2]. NormalaDaud-"The Influence of Quality of Work Life Organizational Commitment: A Study on Academic Staff in Public Institution of Higher Learning in Malaysia"Faculty of Business Management UniversitiTeknologi MARA Shah Alam, Selangor, Malaysia-978-1-4244-86182/1 /\$26. . 21 IEEE

[3]. Seyed Mehdi Hosseini "Quality of work life(QWL) and its relationship with performance"- PHD - Islamic Azad University Of Firouzkooh Branch, Tehran, Iran- 978-14244-6932-1/1/\$26. (C) 1 IEEE

[4]. HÉLÈNE DENIS "Matrix Structures, Quality of Working Life, and Engineering Productivity"- IEEE TRANSACTIONS ON ENGINEERING MANAGEMENT, VOL. EM-33, NO. 3, AUGUST 1986- 18-9391 /86/ 8 148S 1. (C) 1986 IEEE

[5]. Rachel Samuel "Work-Life Balance and Quality of Life in the New Career"- Faculty of Business Management, UiTM, Melaka, Malaysia-978-1-4673- 2 -9/11/\$26. (C2 11 Crown

[6]. NonnalaDaud and Shah Alam "Quality of Work Life and Organizational Commitment Amongst Academic Staff: Empirical Evidence from Malaysia"- Faculty of Business Management UniversitiTeknologi MARA Shah Alam, Selangor, Malaysia-978-1-4244-8618-2/1 /\$26. . 21 IEEE

[7]. ZHU Su-li “Analysis of Utility of Employee's Quality of Working Life and Assessment Model"- School of Management, Huazhong University of Science and Technology, P.R.China.- 1-4244-2388- / 8/\$2 . C2 8 IEEE

[8]. William E. Kiernan and Knutson "Quality of work life" [9]. Daud, N. (2 1 ). Investigating the relationship between QWL and organizational commitment amongst employees in Malaysian firms. International journal of Business and Management. 5(1), 75-82. 